\title{
PROGRAM BIMBINGAN DAN KONSELING EKOLOGIS BAGI ANAK DENGAN ADHD (ATTENTION DEFISIT HYPERACTIVITY DISORDER)
}

\author{
Melina Lestari \\ Program Studi Bimbingan dan Konseling, FIPPS, \\ Universitas Indraprasta PGRI \\ Email: melinalestari@yahoo.co.id
}

\begin{abstract}
Children with ADHD have difficulty focusing attention, they can not sort out what they should pay attention to, hyperactive and perform an impulsive behavior. The aim of this study is: 1)To know the picture of a child with ADHD; 2) Analyze problematics, needs, potentials; and 3) What kind of ecological guidance and counseling programs for children with ADHD. This research was conducted in a kindergarten located in Bandung regency, using case study method with qualitative approach by doing direct observation to children with $A D H D$ and interviewing to teachers and caregivers of ADHD children. Guidelines for observation and interviews are made by the authors themselves. The results show that children with ADHD are not able to talk like children on his age, unable to follow activities in the classroom, he is always on the move, but in this case he has never seen tantrum. Based on the problematic analysis, the needs and potentials of children with ADHD require comprehensive interventions from various stakeholders, Ecological guidance and counseling programs for children with ADHD do not directly provide intervention to children but provide services to teachers and parents so as to be a good environment for Child growth.
\end{abstract}

Keyword: Guidance and Counseling Program, Ecologies, and Children with ADHD

\begin{abstract}
ABSTRAK
Anak dengan ADHD memiliki kesulitan dalam pemusatan perhatian, mereka tidak dapat memilah apa yang harus mereka perhatikan, hiperaktif dan melakukan perilaku yang impulsif. Penelitian ini bertujuan: 1) untuk mengetahui gambaran anak dengan ADHD, 2) menganalisis problematika, kebutuhan, potensi, dan 3) seperti apa program bimbingan dan konseling ekologis bagi anak dengan ADHD. Penelitain ini dilakukan di sebuah Taman Kanak-kanak yang berada di kabupaten Bandung, menggunakan metode studi kasus dengan pendekatan kualitatif dengan melakukan observasi langsung terhadap anak dengan ADHD dan melakukan wawancara kepada guru dan pengasuh anak ADHD. Pedoman observasi dan wawancara di buat sendiri oleh penulis. Hasil penelitian menunjukan anak dengan ADHD adalah belum dapat berbicara seperti anak-anak seusianya, tidak dapat mengikuti kegiatan di kelas ia selalu bergerak, namun pada kasus ini belum pernah terlihat tantrum. Berdasarkan analisis problematika, kebutuhan dan potensi anak dengan ADHD membutuhkan Intervensi yang komprehensif dari berbagai pihak yang terkait, Program bimbingan dan konseling ekologis bagi anak dengan ADHD tidak langsung memberikan intervensi terhadap anak namun memberikan kegiatan layanan terhadap guru dan orang tua sehingga menjadi lingkungan yang baik bagi tumbuh kembang anak.
\end{abstract}

Kata kunci: Program Bimbingan dan Konseling, Ekologis, Anak ADHD 


\section{PENDAHULUAN}

\begin{abstract}
ADHD atau Attention Defisit Hyperactivity Disorder adalah individu yang memiliki gangguan dalam pemusatan perhatian dan hiperaktif. Anak dengan ADHD ini memiliki kesulitan dalam pemusatan perhatian, mereka tidak dapat memilah apa yang harus mereka perhatikan, hiperaktif dan melakukan perilaku yang impulsif (Baihaqi dan Sugiarmin, 2014: 2; Kosasih, 2012: 19). Penyebab pasti dari ADHD belum ditentukan. Namun sejumlah penyebab telah diajukan oleh beberapa peneliti, seperti tingkat yang rendah dari neurotransmitter (alat pengirim pesan kimia dalam otak) tertentu, abnormalitas prakelahiran dan pascakelahiran, dan racun dari lingkungan, seperti mangaan. $30 \%$ sampai $50 \%$ dari anak-anak penderita ADHD memiliki saudara atau orang tua yang juga mengalami gangguan tersebut (Santrock 2007: 258-259).
\end{abstract}

Anak dengan ADHD sering mempunyai permasalahan di sekolah dimana aturan dan prosedur-prosedur sekolah mengharuskan mereka untuk banyak duduk, tetap fokus pada pelajaran, dan berada dikelas dalam mengerjakan tugas-tugas akademik dan diskusi. Mereka mendapatkan pendampingan dari asisten guru yang secara khusus, selain itu merekapun ditempatkan di kelas yang lebih kecil. Namun bagaimanapun, antara $85 \%$ dan $90 \%$ dari anak ADHD masih dilayani secara umum di kelas reguler (Santrock, 2007: 259). Hal tersebut pada akhirnya akan membuat anak dengan ADHD mengalami berbagai macam tekanan dalam rangkaian proses pencapaian perkembangan yang optimal.

Bimbingan dan konseling sebagai bagian dari pendidikan turut serta dalam pemberian layanan bagi anak berkebutuhan khusus dalam seting pendidikan inklusi. Bimbingan dan konseling adalah upaya pedagogis untuk memfasilitasi perkembangan individu dari kondisi apa adanya kepada kondisi bagaimana seharusnya sesuai dengan potensi yang dimilikinya (Kartadinata, 2011: 23-24). Melalui bimbingan dan konseling, diharapkan seluruh anak akan dapat berkembang secara optimal baik yang ada pada kategori anak berkebutuhan khusus atau siswa pada umumnya.

Dalam memberikan layanan kepada anak berkebutuhan khusus diperlukan kolaborasi dari berbagai pihak agar hasil yang dicapai dapat optimal. Seperti yang dilakukan para konselor di Czechoslovakia yang dapat diterapkan juga diberbagai negara bahwa peranan konselor sekolah dalam menangani anak berkebutuhan khusus tidak sebatas memberikan layanan bagi siswa yang memiliki kebutuhan khusus saja, akan tetapi harus memiliki kemampuan dalam berkolaborasi dengan teman sejawat dalam hal ini guru anak berkebutuhan khusus dan guru kelas (Habib, 2014).

Pendekatan ekologis tidak terbatas kepada lingkungan sekolah saja, akan tetapi dalam lingkungan keluarga dan kelompok sosial. Konseli dalam bimbingan dan konseling ekologi adalah individu, keluarga, dan kelompok sosial. Pendekatan ini pun membuka peluang bagi bimbingan dan konseling untuk memperluas jangkauan garapan dan target populasi layanan (Kartadinata, 2011: 89).

Bimbingan mengandung ragam teknik yang lebih bersifat pedagogis untuk memfasilitasi perkembangan konseli dalam upaya mengembangkan perilaku-perilaku jangka panjang secara sehat dan mengambangkan lingkungan perkembangan yang membuka akses luas kepada konseli, jelasnya peserta didik untuk memperoleh sukses dalam belajar (Kartadinata, 2011: 23). Berbagai teknik dipergunakan dalam bimbingan, perkembangan anak dengan ADHD memerlukan lingkungan perkembangan yang memadai, untuk mencapai hal tersebut salah satu cara yang dapat guru bimbingan dan konseling lakukan adalah berkolaborasi dengan orang tua, agar lingkungan perkembangan yang kondusif tidak hanya di sekolah saja.

Jika siswa, orang tua, guru dan sekolah tumbuh dalam suatu lingkungan dengan keterbukaan dan sensitivitas yang sangat kondusif bagi tiap individu dan mempunyai kesadaran pembaruan untuk setiap misinya, maka suasana kepercayaan dan kerja sama yang meningkat dapat tercipta. Keterlibatan semua orang dalam mempersiapkan siswa-siswa yang memiliki hambatan dalam kehidupan masyarakat yang lebih terbuka harus saling dibicarakan (Smith, 2014: 52-53).

Dalam penelitian ini akan dibahas mengenai bagaimana gambaran anak dengan ADHD dan program bimbingan dan konseling seperti apa yang dapat diberikan agar perkembangannya dapat optimal. 


\section{METODE}

Penelitian ini menggunakan pendekatan kualitatif dengan metode studi kasus. Teknik pengumpulan data adalah melalui (1) observasi terhadap anak ADHD dan perlakuan lingkungan terhadap anak ADHD; (2) wawancara terhadap guru dan orang tua; dan (3) dokumentasi yang berkaitan dengan anak ADHD.

Partisipan penelitian ini adalah anak dengan ADHD yang bersekolah di PAUD Katolik Gratias, guru dan orang tua anak tersebut yang berada di jalan Jaksa Naranata Timur No. 161 Baleendah Kabupaten Bandung. Instrumen yang dikembangkan adalah pedoman observasi untuk melihat perilaku anak dan pedoman wawancara untuk gurun dan orang tua yang dibuat sendiri oleh peneliti.

\section{HASIL DAN PEMBAHASAN}

\section{Profil G}

Berdasarkan dokumentasi berupa formulir pendaftaran siswa Tak ada foto dalam formulir pendaftaran siswa yang telah diisi oleh ibu $G$. Penulis mendapat data $G$ yang terdiri dari nama, jenis kelamin, tempat tanggal lahir yang menunjukan bahwa usia $\mathrm{G}$ yang hampir 4 tahun, $\mathrm{G}$ adalah anak kedua dari dua bersaudara dan yang terakhir adalah agama.

Penulispun mendapatkan sedikit data tentang ayah dan ibu G. G dan ayahnya memiliki tanggal kelahiran yang sama, ayah $G$ berusia 35 tahun, pekerjaannya sebagai Dokter umum, ada hal yang menarik $G$ dan ayaknya berbeda agama. $\mathrm{G}$ mengikuti agama ibunya, ibu $\mathrm{G}$ seusia dengan ayahnya, dan memiliki profesi yang sama pula.

Berdasarkan hasil observasi $G$ selalu pergi ke sekolah namun tidak pernah mengikuti kegiatan sekolah. Aktifitas G di kelas: jalanjalan mengelilingi rumah pemilik sekolah(sekolah merangkap rumah tinggal), main dengan tukang sayur (memainkan ikan, sayur dan barang dagangan lainya), main sepeda, makan makanan ringan yang disediakan pemilik sekolah, memainkan mainan di sekolah sendirian. Saat istirahat, G tidak ikut serta bermain dengan teman-temannya. $G$ melihat temannya bermain dan ketika teman-temannya kembali ke kelas dia mencoba permainan yang sebelumnya dimainkan oleh teman-temannya.

$\mathrm{G}$ mudah dekat dengan orang dewasa, bahkan pada orang asing. Hampir setiap hari di lingkungan rumah dan sekolah $G$ seorang tukang sayur berkeliling untuk menjajakan dagangannya, G selalu ingin di gendong oleh tukang sayur tersebut. Pada kesempatan lain, G ingin dipangku oleh seorang ibu yang sedang menunggu anaknya pulang sekolah (ibu teman sekolah $G$ ) yang baru ia kenal. Bahkan $G$ ingin ikut pulang dengan penulis saat kegiatan sekolah usai.

G seperti yang acuh tak acuh ketika ditanya, namun ketika dipanggil menyahut. Kata-kata yang G sebutkan: ni ayam (ini ayam), tita yeye (ikan lele), bu cis (ibu saya mau makan sosis), bobo cici (foto lagi), eh yaya pupupupupupu (eh ada kupu-kupu), tut (takut) dan banyak kata-kata yang tidak dipahami. G suka sesuatu yang bergerak, seperti kupu-kupu, ikan, mainan lele yang bergerak, mainan ayamayaman, namun takut pada mainan yg bersuara. Terkadang saat berjalan, kepala $\mathrm{G}$ miring ke kiri.

Menurut gurunya, $G$ lebih suka main sendiri, tidak bisa duduk lama, menghindari kontak mata, nampak acuh tak acuh, tidak memahami perintah. Saat guru melarang siswa lain untuk mendekati $G$ karena ia sedang memasukan batu ke dalam bak truk mainan, $G$ menangis (gurunya mengira bahwa $G$ sedang tidak mendengar perkataan guru). $\mathrm{G}$ pun belum berhasil dalam toilet training, $\mathrm{G}$ baru memberi tahu guru jika ia buang air setelah mengompol atau buang air besar di celana.

Wawancara dilakukan terhadap guru dan tetangga $\mathrm{G}$, penulis tidak dapat menemui orang tua $G$ dikarenakan orang tua $G$ sangat sibuk, keduanya berprofesi sebagai dokter. Pergi praktek di klinik pagi sampai siang, lalu istirahat sejenak dirumah, sore hari sampai malam kembali bekerja. Kebersamaan dengan orang tua hanya di hari sabtu dan minggu. Saat $\mathrm{G}$ masih kecil, G sering didudukan di high chair dan menonton televisi sementara pembantunya mengerjakan pekerjaan rumah. $\mathrm{G}$ dilarang main kotor-kotoran dan hanya dapat bermain di luar rumah jika orang tua sedang tidak ada.

Dirumah (bahkan di sekolah pun) sering makan makanan cepat saji seperti sosis, nugget, pasta dan mie. Kakak $G$ pun memiliki gejala yang sama dengan $G$ yaitu belum bisa bicara (konon ADHD), saat ini kakak G sedang melakukan proses terapi. Namun $G$ belum pernah diberi intervensi tertentu dari ahli.

Ibunya menginformasikan kepada guru bahwa $G$ terdiagnosa ADHD, namun tidak 
demikian dengan sang ayah, ayahnya mengatakan bahwa $G$ hanya terlambat bicara seperti ia saat masih kecil. G pernah mengalami patah kaki namun orang tua baru mengetahui setelah beberapa hari. Ayah G konon memiliki perilaku yang kasar terhadap pasien. Sang ibu secara fisik nampak kurus dan terlihat tidak bisa mengurus diri.

Rumah $\mathrm{G}$ dekat dengan rumah paman dan bibi dari ibu, sang paman dan bibi G memberikan perhatian pada proses pendidikan $G$ disekolah, seperti berdiskusi mengenai perkembangan $\mathrm{G}$ dengan guru $\mathrm{G}$ disekolah. Banyak tetangga yang mengenal G. Ketika $G$ berjalan-jalan beberapa tetangga menyapa $G$, namun $\mathrm{G}$ nampak acuh tak acuh.

\section{Problematika}

$\mathrm{G}$ belum dapat berkomunikasi verbal atau berbicara seperti anak-anak seusianya. Butuh waktu yang sedikit lama agar dapat memahami apa yang ia inginkan. Kata-kata yang keluar dari mulutnya terkadang hanya berbentuk suku kata, bahkan ada yang sama sekali tidak dipahami.

Selain itu, G pun tidak dapat mengikuti kegiatan di kelas. Perintah yang diberikan oleh guru pun belum dapat $\mathrm{G}$ pahami, tidak ada tugas dari proses pembelajaran di kelas yang dapat $\mathrm{G}$ kerjakan. Saat istirahat tiba, G hanya melihat teman-temannya yang sedang bermain bersama, ia tidak turut serta dalam permainan. Hal ini dapat diartikan bahwa $\mathrm{G}$ belum bisa berbaur dengan teman-teman seusianya, bahkan jika ada teman yang mendekati $\mathrm{G}$ untuk main bersama, $\mathrm{G}$ terlihat menghindar. Hal-hal yang dikemukakan di atas sesuai dengan oleh Muro and Kottman (1995: 235) bahwa anak ADHD memiliki masalah dalam area perilaku, hubungan sosial, fungsi kognitif, fungsi emosi dan fungsi fisik. Mereka juga memiliki kesulitan dalam bidang akademik dan fungsi dalam kelas yang dapat sangat berpengaruh terhadap proses belajar. Selain itu banyak anak penderita ADHD sukar didisiplinkan, memiliki toleransi yang rendah terhadap rasa frustrasi, dan memiliki masalah dalam hubungan sebaya (Santrock, 2007: 258).

Problematika lain yang dihadapi $\mathrm{G}$ adalah ia belum menguasai keterampilan buang air besar/ kecil di kamar mandi. Bahkan awal masuk sekolah $\mathrm{G}$ masih menggunakan popok. Setelah guru melarang $\mathrm{G}$ menggunakan popok, $\mathrm{G}$ baru memberi tahu guru bahwa dia buang air setelah terjadi (ngompol atau buang air besar di celana).

Problematika yang dirasakan oleh guru G adalah guru belum dapat menemukan pendekatan yang efektif untuk metode pembelajaran. Guru masih bingung mengenai intervensi apa yang yang sebaiknya diberikan kepada $G$ agar $G$ dapat menikmati pendidikan seperti teman-temannya yang lain. Selain itu, guru juga merasa kesulitan dalam berkolaborasi dengan orang tua $\mathrm{G}$. Banyak hal yang ingin guru sampaiakan terkait dengan perkembangan $G$, namun orang tua $\mathrm{G}$ nampak kurang peduli dan sulit menerima masukan dari guru.

Problem yang dimiliki G tidak dapat lepas dari peran orang tua. Bukan sesuatu yang mudah untuk dihadapi ketika memiliki anak berkebutuhan khusus, terlebih orang tua $G$ memiliki dua putra sekaligus yang terdiagnosa ADHD. Tentu ini sangat berat dirasakan. Perilaku kasar yang nampak dari sang ayah, fisik ibu yang sangat kurus dan kurang dapat mengurus diri dapat menjadi indikator bahwa orang tua $G$ kemungkinan mengalami tekanan psikologis. Hal ini dapat dikaitkan dengan pendapat Damrosch dan Perry dalam Setiono (2011: 158-159) mengenai reaksi orang tua saat memiliki anak berkebutuhan khusus (Ayah: mourning model solnit and stark (seperti "ditinggal meninggal" oleh harapannya memiliki bayi yg "sempurna"). Terdapat 3 kategori, pertama shock setelah kelahiran anak; kedua disorganisasi emosi dengan menyalahkan dokter, diri sendiri, Tuhan; ketiga reorganisasi emosi, artinya mengintegrasikan reaksi intelektual dan emosional dalam mengasuh anak, secara realistik menghargai, menerima kekuatan dan kelebihan anak, sekaligus mencintai anak. Ibu: lebih banyak mengalami emosi model Olshansky, yaitu pola emosi "naikturun" sepanjang kehidupan anak sepanjang kehidupan anak.

Selain itu, orang tua G kurang memberikan waktu yang banyak untuk bercengkerama dengan anak-anaknya. Kemungkinan hal itu dilakukan karena mereka membutuhkan banyak dana untuk pemberian terapi untuk anak-anaknya, terutama kakak G.

\section{Potensi}

ADHD ditemukan pada setiap tingkatan inteligensi. ADHD dapat menutupi inteligensi pada anak-anak berbakat dan akan menunjukan prestasi rata-rata atau dibawah rata-rata (Baihaqi 
dan Sugiarmin, 2014:16). Sehingga mungkin saja $\mathrm{G}$ memiliki inteligensi yang tinggi atau ratarata, namun tertutupi oleh keADHDannya dan pasti memiliki bakat yang harus dikembangkan oleh lingkungan Hal positif yang ditemukan di sekolah adalah $\mathrm{G}$ tidak pernah tantrum.

\section{Kebutuhan}

Melihat problematika dari $\mathrm{G}$ yang belum diberi treatmen khusus, maka $\mathrm{G}$ membutuhkan Intervensi yang komprehensif dari berbagai pihak yang terkait, dari berbagai profesi, seperti dokter yang akan memberikan intervensi medis, guru ABK yang akan memberikan intervensi pendidikan, terapis yang akan memberikan treatmen berupa terapi wicara dan lain sebagainya. hal ini selaras dengan pendapat Baihaqi dan Sugiarmin (2014: ) bahwa anak ADHD harus diberi intervensi komprehensif dari berbagai pihak, seperti intervensi pendidikan, intervensi perilaku, intervensi sosialisasi, intervensi medis, dan lain sebagainya. Agar dapat lebih mudah untuk dipahami, berikut disajikan dalam bentuk gambar bagaimana intervensi yang komprehensif bagi anak ADHD.

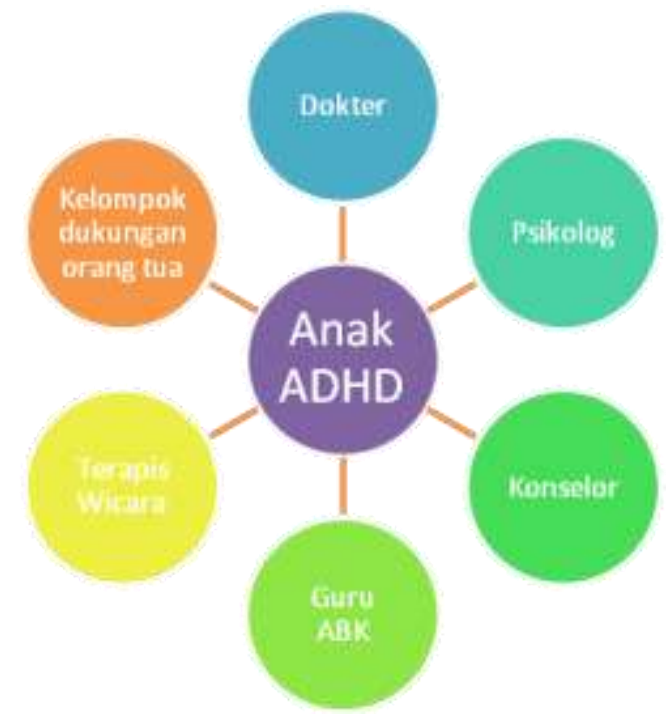

Gambar 1

Intervensi komprehensif dari berbagai multidisiplin bagi anak ADHD

Selain itu G pun membutuhkan suatu lingkungan perkembangan yang kondusif agar ia dapat berkembang optimal. Lingkungan terdekat $\mathrm{G}$ saat ini adalah keluarga dan sekolah atau dalam teori yang digagas oleh Bronfenbrenner (1979:22)
Microsystem merupakan lingkungan yang paling dekat kepada individu, seperti keluarga, sekolah, teman sebaya, lapisan ini terdiri dari lingkungan fisik dan orang (seperti menyangkut status sosial ekonomi dan latar belakang pendidikan orang tua).

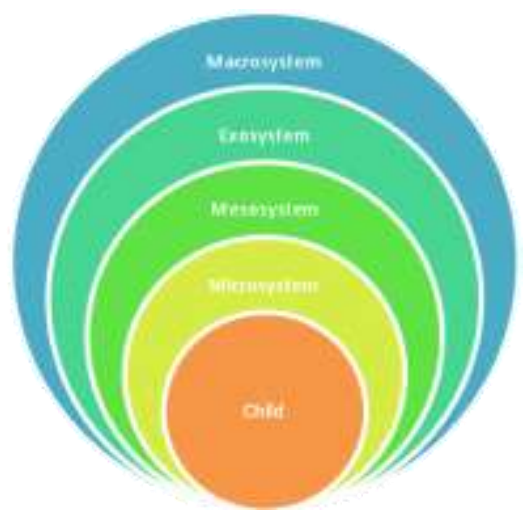

Gambar 2

Lingkungan perkembangan individu (Bronfrenbrenner, 1979) 
Berdasarkan asumsi-asumsi diatas, maka program intervensi yang akan diberikan kepada $\mathrm{G}$ akan melibatkan guru dan orang tua didalamnya. Pemberian intervensi kepada orang tua diharapkan dapat mengoptimalkan potensi G, ini ditegaskan dalam konsep Family Quality of Life (Chiu, 2013), yang dapat digambarkan sebagai berikut:

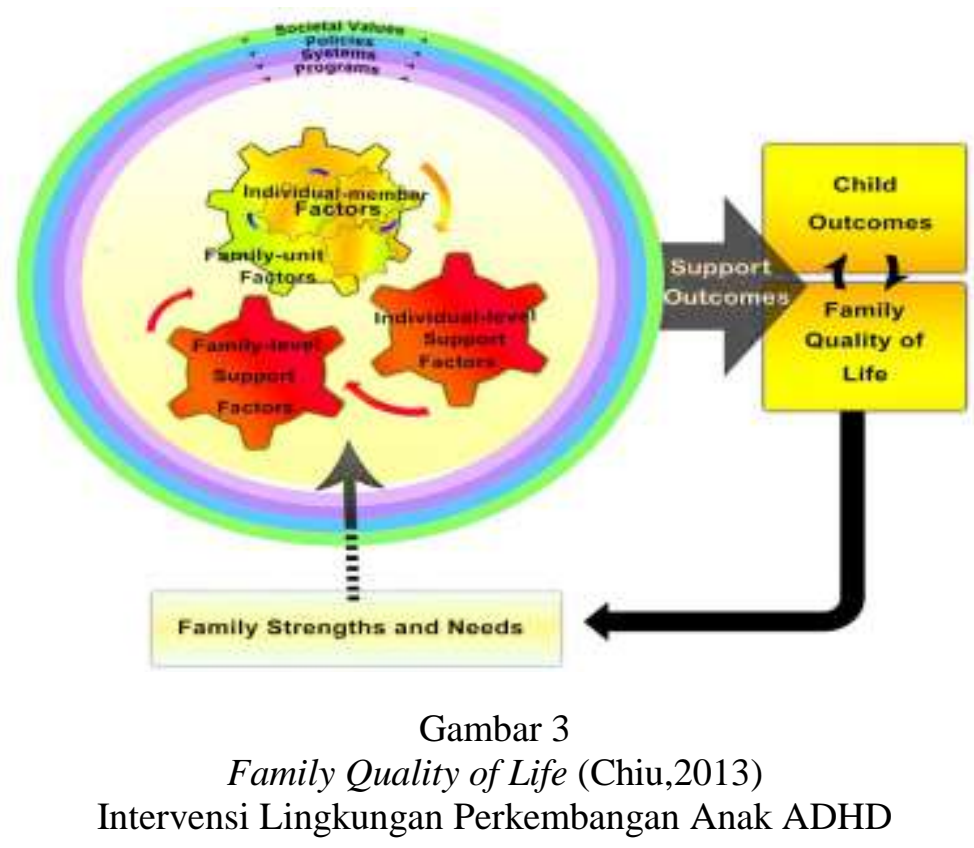

Pemberian intervensi pada anak ADHD, tidak bisa dari satu pihak saja, dibutuhkan kolaborasi dari berbagai pihak. Dalam program ini konselor, guru dan orang tua akan berkolaborasi dalam optimalisasi perkembangan anak ADHD. Sehingga program ini akan diberikan pula kepada guru dan orang tua.
Diharapkan dengan memberikan perlakuan terhadap guru dan orang tua, akan merubah pula perlakuan mereka terhadap anak ADHD. sehingga anak ADHD dapat berkembang dengan optimal segala potensi yang dimilikinya. Jika digambarkan melalui bagan, maka akan tergambar seperti ini:

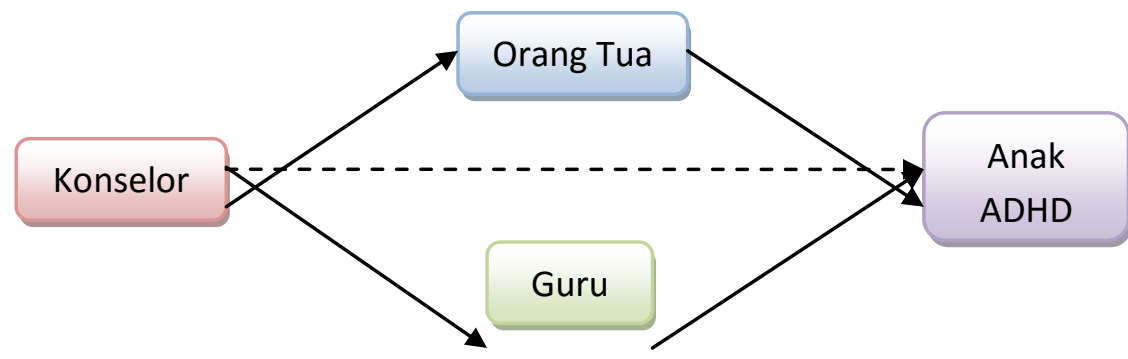

Gambar 4

Intervensi Lingkungan Perkembangan Anak ADHD

\section{Program bagi Anak ADHD}

Program yang diberikan kepada $G$ sebagai anak ADHD tidak langsung diberikan oleh konselor. Konselor memberikan assesmen kepada $G$ dengan cara mengobservasi $G$ di lingkungan sekolah serta mewawancarai guru dan pengasuh $G$ untuk mengetahui lebih dalam mengenai $G$ di lingkungan rumah dan masyarakat. Dari hasil assesmen tersebut dapat ditarik suatu kesimpulan sementara mengenai problematika, kebutuhan, dan potensi yang dimiliki $\mathrm{G}$ yang telah disampaikan pada bagian sebelumnya dalam buku ini. 


\section{Program bagi Guru}

Terdapat dua program intervensi yang akan diberikan kepada guru $\mathrm{G}$ yaitu, konsultasi mengenai anak ADHD dan Pendidikan Inklusi dimana kontennya akan dijelaskan sebagai berikut:

\section{Anak ADHD}

Guru dapat berdiskusi seputar anak ADHD, mencakup apa itu ADHD, bagaimana karakteristik anak ADHD, bagaimana memahami anak ADHD, adakah contoh anak ADHD yang berprestasi dan sebagainya. Selain itu penulis memotivasi guru agar terus mencari tahu bagaimana cara intervensi pendidikan dalam menangani anak ADHD melalui berbagai cara, misalkan mencari tahu kepada ahli, membaca buku-buku dan lain sebagainya.

\section{Pendidikan Inklusi}

Sebenarnya PAUD Gratias bukanlah sekolah inklusi, namun pihak sekolah memang tidak membatasi siswa yang dapat sekolah disana, seluruh siswa yang mendaftar diterima dengan senang hati. Penulis mengajak guru untuk melaksanakan sekolah inklusi, seperti memberi pemahaman mengenai konsep pendidikan inklusif, bagaimana penyelenggaraannya, apa yang harus dipersiapkan dalam penyelenggaraannya, keuntungan dan kelemahan pendidikan inklusif dan lain sebagainya.

\section{Program Bagi Orang Tua}

Beberapa program akan diberikan kepada orang tua $\mathrm{G}$, diantaranya asesmen mengenai perlakuan yang selama ini diberikan, konseling keluarga, dan pendampingan dalam mengikuti komunitas orang tua yang memiliki anak ADHD.

\section{Asesmen dalam bentuk catatan harian.}

Penulis belum mengetahui bagaimana cara orang tua $G$ memperlakukan $G$ dalam persepsi mereka. Yang penulis tahu dari sumbersumber lain seperti dari guru, pengasuh dan tetangga G. Karena itu, penulis merancang sebuah asesmen yang tidak biasa. Hal yang ingin digali adalah bagaimana keseharian $G$ dengan orang tuanya di rumah, selain itu didalamnya terdapat tips pengasuhan positif bagi anak berkebutuhan khusus sekaligus sebagai edukasi bagi orang tua $\mathrm{G}$, kalimat bijak dari beberapa tokoh dan syair dari dua lagu yang sangat menyetuh. Diharapkan orang tua mau secara terbuka menuliskan kegiatan yang mereka lakukan dengan $\mathrm{G}$, dan memiliki sedikit perubahan dalam berkomunikasi dengan pihak sekolah karena di bagian akhir asesemen ada nomor telepon yang dapat dihubungi orang tua agar dapat berkomunikasi lebih mendalam dengan konselor atau guru G. Akhirnya dari hasil asesmen ini, dapat menjadi bahan pertimbangan dalam pembutan program intervensi bagi orang tua yang sesuai dengan kebutuhan orang tua.

\section{Konseling keluarga}

Berdasarkan asumsi yang telah dipaparkan pada bagian sebelumnya, maka dalam pemberian konseling bagi orang tua G menggunakan Cognitive Behavior Marital Family Therapy. Hal ini dikarenakan asumsi utama cognitive behavior marital family therapy adalah bahwa perilaku bermasalah dan kognisi dipelajari dan dikelola oleh interaksi pola perilaku berulang tertentu. Pola-pola interaksi mungkin melibatkan imitasi, operan conditioning, pengkondisian klasik, atau beberapa kombinasi dari ini. Cognitive Behavioural Marital Family Therapy membantu klien mengganggu pola interaksi dengan melatih mereka dalam keterampilan yang dibutuhkan untuk membentuk dan memperkuat perilaku tidak bermasalah pada anggota keluarga lainnya dan dengan menantang pengetahuan negatif mereka dalam memeliharan masalah. Misalnya, dalam pelatihan perilaku orangtua $G$, orang tua $\mathrm{G}$ belajar untuk memperkuat perilaku positif pada diri mereka dalam memperlakukan G. Dalam terapi perilaku perkawinan tradisional, pasangan belajar untuk saling memperkuat satu sama lain untuk terlibat dalam perilaku positif daripada perilaku negatif interpersonal.

Restrukturisasi kognitif adalah intervensi utama yang digunakan untuk menantang kognisi negatif. Anggota keluarga diundang untuk memantau dan merekam situasi yang menimbulkan kognisi tertentu, dan dampak selanjutnya terhadap suasana hati dan perilaku interpersonal. Ketika kognisi negatif diidentifikasi dengan cara ini, klien dilatih dalam menantang ini dengan menemukan bukti nyata untuk mendukung atau menentang mereka. Ketika kognisi negatif tidak didukung, klien diundang untuk merevisinya sehingga kognisi baru muncul. Mereka juga diundang untuk merekam dampak kognisi yang direvisi pada suasana hati dan perilaku interpersonal. 
Dalam terapi perilaku pasangan integratif membangun penerimaan yang digunakan untuk membantu pasangan beradaptasi dengan aspek yang tidak berubah dari hubungan mereka. Ini melibatkan empati disekitar masalah pasangan; detasemen dari masalah; bangunan toleransi; dan kepedulian terhadap diri (Carr, 2006).

Dalam memudahkan intervensi maka konselor akan memberikan suatu Catatan pikiran yang akan diisi bersama-sama dengan orang tua G. Proses pembuatan Catatan Pikiran yang terdiri dari tujuh kolom (Greenberger and Padesky, 1995) adalah sebagai berikut :

1. Situation (menggambarkan situasi yang dialami)

2. Moods (mengidentifikasi Mood dan memberi rating mood dalam skala $1-100$

3. Automatic Thought (Apa yang dipikirkan sebelumnya?, pikiran lain?, Image? dan Pikiran Panas)

4. Evidence that supports the hot thought (bukti yang mendukung pikiran panas)

5. Evidence that does not support the hot thought (bukti yang tidak mendukung pikiran panas)

6. Alternatif / Balance Thought (pikiran alternatif atau pikiran seimbang)

7. Rate Moods Now (Rating Mood yang dirasakan sekarang)

\section{Advokasi mengikuti komunitas}

Salah satu fungsi konseling adalah advokasi yang bertujuan agar menghasilkan kondisi pembelaan terhadap berbagai bentuk pengingkaran hak-hak perkembangan (Hartono dan Soedarmadji, 2013: 37). Mengapa orang tua $\mathrm{G}$ harus masuk pada komunitas orang tua yang memiliki anak ADHD? Banyak keuntungan yang bisa didapat apabila keluarga mengikiti komonitas, diantaranya: 1) lingkungan yang memberikan dukungan kepada keluarga, dan kehendak serta kedermawanan yang alami untuk membantu keluarga yang membutuhkan; 2) sistem pendidikan yang efektif, banyak sistem pendidikan yang diorganisir oleh komunitas dan tersebar dari mulut kemulut; 3) komunitas religius memegang peran penting dalam mengembangkan spiritual well-being untuk keluarga dan memberikan dukungan di bidang lainnya; 4) program layanan diberikan oleh komunitas dalam membantu keluarga yang kurang mampu agar dapat ditolong ( saling berbagi); 5) menciptakan lingkungan yang aman dan sehat (Setiono, 2011:192-193)

\section{SIMPULAN DAN SARAN}

Berdasarkan hasil pengumpulan, pengolahan dan analisis data mengenai anak dengan ADHD dan program bimbingan dan konseling ekologis seperti yang telah diuraikan sebelumnya, maka simpulan yang dapat diambil adalah sebagai berikut:

Gambaran anak dengan ADHD adalah G belum dapat berbicara seperti anak-anak seusianya, tidak dapat mengikuti kegiatan di kelas karena $\mathrm{G}$ selalu bergerak, namun $\mathrm{G}$ belum pernah terlihat tantrum. Berdasarkan analisis problematika, kebutuhan dan potensi anak dengan ADHD adalah G membutuhkan Intervensi yang komprehensif dari berbagai pihak yang terkait, dari berbagai profesi, seperti dokter yang akan memberikan intervensi medis, guru ABK yang akan memberikan intervensi pendidikan, terapis yang akan memberikan treatmen berupa terapi wicara dan lain sebagainya.

Program bimbingan dan konseling ekologis bagi anak dengan ADHD tidak langsung memberikan intervensi terhadap anak namun memberikan kegiatan layanan terhadap guru dan orang tua sehingga menjadi lingkungan yang baik bagi tumbuh kembang anak dengan ADHD. Program bagi guru terdiri dari dua kegiatan, yaitu pemberian layanan informasi mengenai anak ADHD dan memberikan edukasi mengenai konsep pendidikan inklusi. Sedangkan program bagi orang tua, penulis mengajak orang tua agar agar melakukan assesment terhadap anaknya, dengan menuliskan catatan harian, melakukan konseling keluarga dan advokasi dalam mengikuti komunitas orang tua yang memiliki anak dengan ADHD.

Adapun saran yang peneliti berikan, adalah sebagai berikut:

\section{Bagi Guru}

Belum semua program yang dibuat oleh penulis dapat terlaksana untuk mengembangkan potensi G. Yang dapat dilaksanakan adalah program asesmen yang diberikan kepada $\mathrm{G}$, melalui observasi langsung terhadap $G$ dan wawancara yang penulis lakukan kepada guru dan pengasuh $G$ untuk menggali lebih banyak tentang G. Konsultasi untuk guru $\mathrm{G}$ mengenai anak ADHD dan pendidikan inklusif dapat 
terlaksana dengan baik setelah asesmen terhadap $\mathrm{G}$ dilakukan. Guru juga harus dapat berkolaborasi dengan orang tua agar perkembangan $\mathrm{G}$ dapat optimal.

\section{Bagi Orang Tua}

Program bagi orang tua belum semua terlaksana, program asesmen sekaligus edukasi bagi orang tua $G$ telah diberikan, namun belum nampak bagaimana respons dari orang tua $G$ dikarenakan program ini diberikan saat pemberian rapot lalu disusul dengan libur semester ganjil. Program yang belum terlaksana adalah konseling keluarga dan advokasi dalam mengikuti komunitas orang tua yang memiliki anak ADHD. Orang tua yang memiliki anak berkebutuhan khusus seyogyanya dapat membuka diri agar dapat memotivasi diri untuk optimalisasi perkembangan anak, mereka pun hendaknya dapat memngikuti suatu komunitas agar dapat saling menguatkan.

\section{REFERENSI}

Baihaqi, M dan Sugiarmin, M. (2014). Memahami dan Membantu Anak ADHD. Bandung: Refika Aditama.

Bronfenbrenner, U. (1979). The Ecology of Human Development: Experiments by Nature and Design. USA: Harvard University Press.

Carr, Alan. (2006). Family Therapy: Concepts, Process and Practice, $2^{\text {nd }} e d$. London: John Wiley \& Sons, Ltd.

Chiu, Chun-Yu. (2013). Family Needs and Family Quality of Life for Taiwanese Families of Children with Intellectual Disability and Developmental Delay. Dissertation. Special Education and the
Graduate Faculty of the University of Kansas.

Greenberger, D and Padesky, CA. (1995). Mind Over Mood: Change How Yuo Feel by Changing the Way You Think. New York USA: The Guilford Press.

Habib, MA. (2014). The Role of the Educational Counsellor in Meeting Special Education Needs (SEN) in Primary Schools of Prague, Czechoslovakia. Bangladesh Education Journal, P 31 - 41.

Hartono dan Soedarmadji, B. (2013). Psikologi Konseling. Jakarta: Kencana Prenada Media Group.

Kartadinata, S. (2011). Menguak Tabir Bimbingan dan Konseling Sebagai Upaya Pedagogis: Kiat Mendidik sebagai Landasan Profesional Tindakan Konselor. Bandung: UPI Press.

, (2011). Kerangka Kerja Bimbingan dan Konseling dalam Pendidikan: Pendekatan Ekologis sebagai Suatu Alternatif. Dalam Suherman dan Budiman, N. Pendidikan dalam Perspektif Bimbingan dan Konseling. Bandung: UPI Press.

Kosasih, E. (2012). Cara Bijak Memahami Anak Berkebutuhan Khusus: Panduan Praktis untuk orang tua, guru, mahasiswa, dosen. Bandung: Yrama Widya.

Muro, JJ and Kottman, T. (1995). Guidance and Counseling in the Elementary and Middle Schools. USA: Brown \& Benchmark Publishers.

Santrock, JW. (2007). Perkembangan Anak. Jakarta: Penerbit Erlangga.

Setiono, K. 2011. Psikologi Keluarga. Bandung: Penerbit Alumni.

Smith, JD. (2014). Pendidikan Inklusif: Konsep dan Penerapan Pembelajaran. Bandung: Nuansa Cendikia. 